\title{
Erratum to: Complete genome sequence of longan witches' broom-associated virus, a novel member of the family Potyviridae
}

\author{
Jang-Kyun Seo ${ }^{1}$ Mi-Kyeong Kim² ${ }^{2}$ Hae-Ryun Kwak ${ }^{2} \cdot$ Jeong-Soo Kim $^{3}$ • \\ Hong-Soo Choi ${ }^{2}$
}

Published online: 7 July 2017

(C) Springer-Verlag GmbH Austria 2017

\section{Erratum to: Arch Virol DOI 10.1007/s00705-017-3405-2}

The prediction of cleavage sites in the polyprotein derived from the genomic sequence of Longan witches' broomassociated virus ( $\mathrm{LWBaV}$ ), as depicted in Fig. $1 \mathrm{C}$ of the article by Seo and colleagues [1], contains a site which does not comply with the standard consensus for the NIaPro mediated processing of potyvirus mature gene products [2]. As already mentioned by authors in the text, the site proposed for the cleavage at the NIb/CP junction is located close to another possible site, which could lead to a slightly larger $\mathrm{CP}$ with a N-terminal sequence starting with the residues AGEMTD..., and a predicted size of 311 amino acids. Until further experimental evidence can be provided, the annotation of the CP of LWBaV should preferably be derived from the predicted standard processing event (LVIETQ/AG) at position 2775 in the viral polyprotein.

The online version of the original article can be found under doi:10.1007/s00705-017-3405-2.

\footnotetext{
Jang-Kyun Seo

jangseo@snu.ac.kr

Hong-Soo Choi

hschoi@korea.kr

1 Department of International Agricultural Technology and Institutes of Green Bio Science and Technology, Seoul National University, Pyeongchang 25354, Republic of Korea

2 Crop Protection Division, National Institute of Agricultural Sciences, Rural Development Administration, Wanju 55365, Republic of Korea

3 Department of Plant Medicals, Andong National University, Andong 36729, Republic of Korea
}

In addition, the numbering corresponding to the position for the P1/HC-Pro cleavage site (EPITYY/SG) in the same Fig. 1C should be corrected to 396. The predicted sizes of the two first gene products of LWBaV should be 396 and 456 amino acids for P1 and HC-Pro, respectively.

\section{References}

1. Seo JK, Kim MK, Kwak HR, Kim JS, Choi HS (2017) Complete genome sequence of longan witches' broom-associates virus, a novel member of the family Potyviridae. Arch Virol. doi:10.1007/ s00705-017-3405-2

2. Adams MJ, Antoniw JF, Beaudoin F (2005) Overview and analysis of the polyprotein cleavage sites in the family Potyviridae. Mol Plant Pathol 6:471-487 